\title{
Attitudes towards compulsory vaccination in Italy: Results from the NAVIDAD multicentre study
}

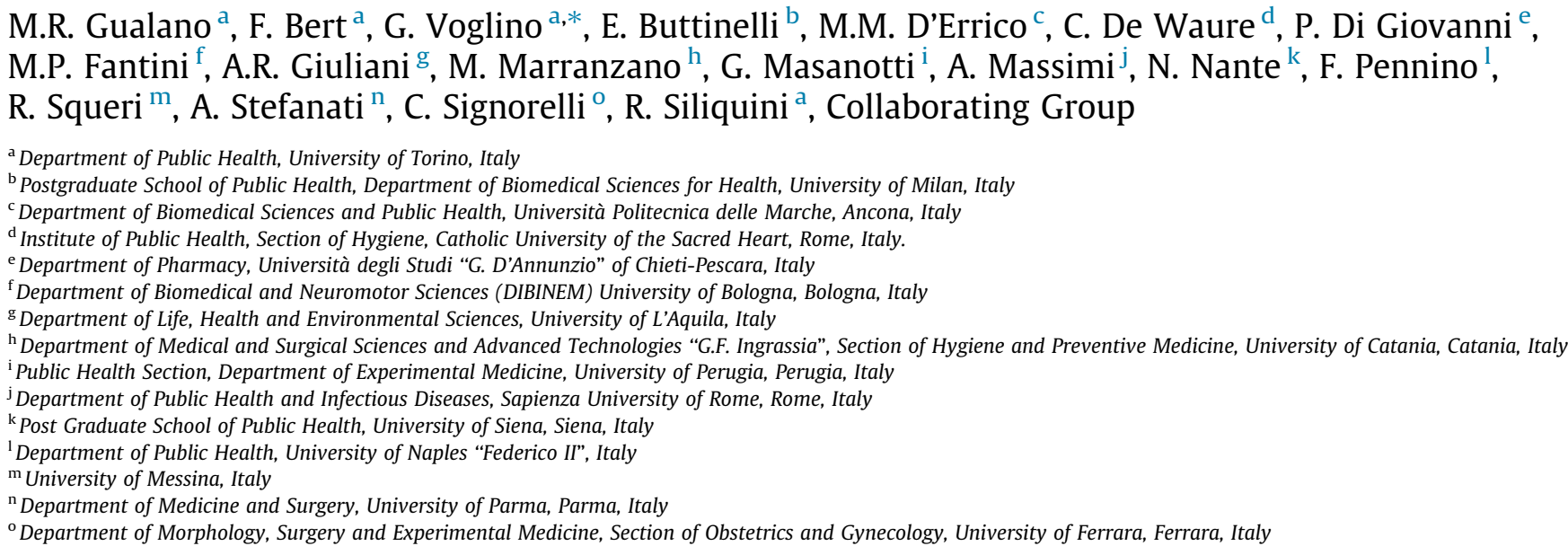

\section{A R T I C L E I N F O}

\section{Article history:}

Received 7 February 2018

Received in revised form 26 March 2018

Accepted 11 April 2018

Available online 2 May 2018

\section{Keywords:}

Mandatory vaccination

Vaccine hesitancy

Attitudes

Pregnancy

Multicentre survey

Italy

\begin{abstract}
A B S T R A C T
Background: Vaccine hesitancy is a considerable issue in European countries and leads to low coverage rates. After a long debate, Italy has made vaccination mandatory for admission to its schools.

Methods: In the NAVIDAD study (a cross-sectional multicentre study), a 63-item questionnaire was administered to 1820 pregnant women from 15 Italian cities. The questionnaire assessed the interviewee's opinion on mandatory vaccines, as well as their socioeconomic status, sources of information about vaccines, confidence in the Italian National Healthcare Service (NHS), and intention to vaccinate their newborn. Results: Information sources play a key role in determining the opinion on restoration of mandatory vaccines; in particular, women who obtained information from anti-vaccination movements are less likely to accept the vaccines (OR: $0.35,95 \% \mathrm{CI}: 0.21-0.58, \mathrm{p}<0.001$ ). Women who had confidence in healthcare professional information agreed more on mandatory vaccination than did the other women $(\mathrm{OR}: 2.66,95 \% \mathrm{CI}$ : $1.62-4.36, \mathrm{p}<0.001$ ); those who perceived that healthcare professionals have economic interest in child immunization and who declared that healthcare providers inform only on vaccinations benefits not on risks were less likely to agree on compulsory vaccination (OR: $0.66, \mathrm{CI} 95 \%$ : $0.46-0.96, \mathrm{p}=0.03$; OR: $0.66, \mathrm{CI} 95 \%$ : $0.46-0.95, \mathrm{p}=0.03$, respectively).

Conclusion: Information sources and confidence towards health professionals are the main determinants of acceptance of mandatory vaccine restoration. To increase the acceptability of the restoration and reduce vaccine hesitancy, these aspects need to be strengthened.
\end{abstract}

(c) 2018 Elsevier Ltd. All rights reserved.

\section{Introduction}

Vaccination appears to be the most effective and cost-effective intervention to reduce the burden of contagious diseases [1-3].
Immunization averts an estimated 2 to 3 million deaths every year; however, an additional 1.5 million deaths could be avoided if global vaccination coverage improved [4]. Today, several vaccines are available and differently administered all over the world.

\footnotetext{
* Corresponding author at: Department of Public Health, University of Torino, Via Santena 5 bis, 10126 Torino, Italy.

E-mail address: gianluca.voglino@unito.it (G. Voglino).
} 
Moreover, immunization rates across countries vary considerably, and an estimated 19.5 million infants worldwide are still not receiving basic vaccines [5]. The Global Vaccine Action Plan (2011-2020) (GVAP) is a framework adopted by all the World Health Organization (WHO) Member States at the Sixty-fifth World Health Assembly in May 2012 to achieve the vision of the Decade of Vaccines (DoV) 2011-2020 of "a world in which all individuals and communities enjoy lives free from vaccine-preventable diseases" [6]. The GVAP sets goals, strategic objectives and indicators to achieve the mission, which is to "improve health by extending by 2020 and beyond the full benefits of immunization to all people, regardless of where they are born, who they are, or where they live" [6].

The European Vaccine Action Plan (2015-2020) (EVAP) developed by the 53 Member States of the Region with the WHO Regional Office for Europe, immunization partners and stakeholders, contributes directly to the goals of the GVAP and the European Region's overall Health 2020 Strategy [7]. Despite efforts, the 2015 regional measles and rubella elimination target was missed. The Region's polio-free status was threatened, and several countries observed a resurgence of diphtheria and pertussis, which also exposed the unpredictability of vaccine supply in the Region [4].

Currently, Europe faces many challenges, including issues with access to vaccine supply and affordable pricing, sustainable domestic financing, resource mobilization, and a growth of antivaccination sentiment and visibility [6]. Many countries and communities are dealing with groups refusing available recommended vaccinations for themselves and/or their children [8-10]. The factors underlying these decisions are different, and there is no single intervention strategy that can solve the problem [11,12]. Vaccines are losing public confidence, and several international organizations (WHO, EU, ECDC) warn against the growing phenomenon of vaccine hesitancy and its impact on decreasing vaccine coverage trends $[13,14]$. This issue has created a need for national immunization programmes to find approaches and strategies to address vaccine hesitancy.

In Italy, for each vaccine included in the National Immunization Schedule (NIS), officials have provided fixed coverage targets considering herd immunity thresholds needed to break infectious disease transmission throughout the population. The 24-months of age coverage target defined in PNPV (Piano Nazionale Prevenzione Vaccinale) was set at $\geq 95 \%$ for the following vaccines: DTPa (diphtheria, tetanus, acellular pertussis), hepatitis B, Hib (Haemophilus influenzae type b), first dose of MPR (measles, mumps, rubella), pneumococcal, meningococcal C, chicken pox, and rotavirus [15]. The HPV vaccine in females and in males should achieve coverage $\geq 70 \%$ at 12 years old. In 2016 , available data on infant vaccines reported that the 24-months of age coverage rates were all beneath the 95\% threshold [16]. These percentages were a long way off from the published PNPV targets and the WHO's recommendations on GVAP. Furthermore, it is important to note that vaccine coverage rates have been declining for several years. Since 2013, the only coverage that has shown an increase in national data was meningococcus [17]. A negative coverage trend has been reported for all the other vaccines, including pneumococcal (88.7\% in 2015 vs $88.4 \%$ in 2016), measles and rubella (which was $90.4 \%$ in 2013 vs $85.3 \%$ in 2015 and slightly up in 2016 but still far from achieving the coverage needed to eliminate the virus) [17]. The general negative trend was also confirmed by the national 36-months of age vaccination coverage for 2016 (relating to children born in 2013). These data are especially useful for monitoring the share of children who were in default of the previous year's vaccination survey and were recovered. The 36-months of age coverage rates showed slightly higher values than those found for the same birth cohort at 24 months of age in the previous year. Recuperation is limited, and 95\% is only achieved for Hib [18].
The national low immunization levels and their negative trends led to the introduction of compulsory vaccination in Italy on 31 July 2017 for ten infectious diseases. Compulsory vaccination has been introduced to guarantee public health safeguards and to reach the coverage targets of the PNPV [19]. Preliminary data from five regions show that compared with 2016, this strategy has led to an increase in vaccine coverage from June to October of 2017 of $1.0 \%$ for the hexavalent vaccine against diphtheria, tetanus, pertussis, poliomyelitis, $H$ influenzae type $b$, and hepatitis $\mathrm{B}$ and $2.9 \%$ for the measles, mumps, and rubella vaccine [20].

In this context, a study named NAVIDAD (Nozioni e Attitudini sui Vaccini dell'Infanzia nelle Donne in Attesa e loro Decisioni), which was started in 2016 and lasted for approximately-one year, was conducted with the aim of analysing the influence of many determinants [21-24] on Italian pregnant women's decisions regarding routine vaccinations of their children [25]. This paper focuses on pregnant women's attitudes towards the compulsory nature of infant vaccinations and its relationship with some vaccine hesitancy determinants as follows: sociodemographic data, information sources, trust in the institution, and knowledge and perceptions on vaccines and preventable infectious diseases [26,27]. The main objective of this paper is to describe pregnant women's attitudes and behaviours towards compulsory nature of paediatric vaccinations, assessing their trustworthiness and acceptability. In particular, we wanted to analyse its possible determinants, considering social determinants, source of information and trust in the National Health System. This information could play a role in future public health policies.

\section{Methods}

A cross-sectional multicentre study was conducted by involving patients in the following Italian cities:

\section{- Bologna, Ferrara, Milan, Parma and Turin were considered from the North of Italy; \\ - Ancona, Perugia, Roma and Siena were considered from the Centre of Italy; \\ - Catania, Chieti-Pescara, L'Aquila, Messina and Naples were con- sidered from the South of Italy.}

Each city was considered in Northern, Central or Southern Italy according to European Parliament constituencies. In particular, North-West and North-East constituencies were considered as North.

The execution of this study was approved by the Ethics Committee of the Hospital "A.O.U. Città della Salute e della Scienza di Torino".

Study subjects (pregnant women over the age of 18 who were able to understand the protocol information and the questionnaire) were enrolled from September 2016 to May 2017 among patients waiting for a gynaecological, ultrasound or haematological examination in the reference hospitals of the cities involved in the study.

Informed consent was obtained after a full explanation of the nature and possible consequences of the study.

The interviews were conducted by two different trained resident doctors from each centre involved. The interviewers were recognizable as researchers, and the interviews were conducted by a doctor who was not directly involved in the patients' care team.

A non-self-compiling paper questionnaire was used during the 25 -min interview of the women involved. The questionnaire was composed of seven sections for a total of 63 items. Each section was investigating the following topics: 
1. The socio-economic framing (patient age, qualification, occupation, etc.);

2. Whether the woman intended to vaccinate her child and for which pathologies;

3. The sources through which the women had sought and obtained information about vaccinations;

4. The degree of confidence of the women in healthcare workers;

5. The perception of the frequency and severity of the major preventable pathologies with vaccinations;

6. An assessment of her vaccine knowledge;

7. The interviewee's opinion on the restoration of mandatory vaccines.

This study focuses on section number 7, the interviewee's opinion on the restoration of mandatory vaccines and how it is influenced by socio-economic framing, willingness to vaccinate the newborn, information sources and confidence in healthcare service (Sections 1, 2, 3 and 4).

\subsection{Population and sample size calculation}

Two different letters were sent to all Italian public health school directors $(n=32)$. Fifteen of these directors agreed to participate in the study. For each city, the sample was defined based on the demographic data of the resident population, considering the number of the newborns in the cities included [28].

Considering the MPR vaccine coverage of $86.7 \%$ [17], it was possible to provide an estimation of the number of interviews necessary to obtain valid data [29-31]. We considered a $-10 \%$ of MPR vaccine coverage as "worst acceptable" for results to find a very conservative value. The confidence level was set at $95 \%$, and the power of the study was considered to be $80 \%$. The sample size was then calculated using the statistical software EpiInfo 7.0. To be more conservative, we required a number of cases in the range between the value determined by the sample size calculation results and that value increased by $30 \%$.

The final sample size was expected to be in the range between 1764 and 2296 subjects involved. For each city, the number of questionnaires required ranges as follows: Ancona (116-151), Bologna (133-172), Catania (132-172), Chieti-Pescara (124-161), Ferrara (120-160), L'Aquila (111-144), Messina (129-168), Milan (138-178), Naples (136-177), Parma (128-176), Perugia (125163), Rome (150-180), Siena (99-129) and Turin (123-175).

\subsection{Statistical analyses}

After the data collection, all participating centres mailed the original paperwork of the questionnaires filled in anonymously to the Department of Public Health and Pediatrics at the University of Turin.

A total of 1820 questionnaires were processed using SPSS 24 Statistical software for Windows.

First, a descriptive analysis of all the variables was conducted. The major outcome was the interviewee's opinion on the restoration of mandatory vaccines. The variables included in the analysis were as follows: the socio-demographic data, any previous pregnancies, the pregnancy quarter, the willingness to vaccinate the newborn, the different ways of obtaining the information and the degree of trust in healthcare workers.

A logistic regression was conducted to estimate the impact of some variables on the above-described outcomes. The covariates included in the final model were selected using a stepwise forward selection process, with the criterion of a $P$ value at univariate $<0.25$ [32]. These associations are expressed as odds ratios (OR) at a $95 \%$ confidence interval $(\mathrm{CI})$, and a $\mathrm{p}$ value $\leq 0.05$ was considered significant for all analyses.

\section{Results}

A total of 1820 pregnant women were interviewed. The following number of women participated from each city: Ancona 120, Bologna 172, Catania 160, Chieti-Pescara 139, Ferrara 140, L'Aquila 123, Messina 81, Milan 203, Naples 140, Parma 29, Perugia 125, Rome 127, Siena 90 and Turin 171. The mean age of the sample was 32.5 years $(S D \pm 5.2$ ). The youngest patient was 18 years old, and the oldest patient was 48 . Most women declared themselves to be Italian (90.8\%), married or living with a partner (91.9\%), primiparous (63.4\%) and at the third trimester of pregnancy (71.9\%). Approximately half of the sample affirmed to be educated at least to the university degree level $(46.8 \%)$. The majority of women declared to be employed (71.8\%); $39.9 \%$ were office workers or teachers, $14.7 \%$ were entrepreneurs or private professionals, $9.3 \%$ were labourers or artisans. Moreover, $7.9 \%$ of the sample had an occupation in the healthcare field.

Of the entire sample, $1.9 \%$ of women declared they would not vaccinate their next child. In regards to information sources, in the overall sample, only $41.8 \%$ of the women obtained information about vaccines from healthcare professionals; $56.9 \%$ declared to have gained information autonomously. The most frequently used information sources were web sites (65.7\%), of which half $(50.4 \%)$ were non-institutional web sites. The second most commonly used information source was word of mouth (47.7\%). Paediatricians were the third source of information in frequency (37.3\%).

The results showed that $92 \%$ of our sample had confidence in healthcare professionals and $86.5 \%$ declared that healthcare professionals are experienced and knowledgeable; only $18.7 \%$ of the interviewed women trusted more private healthcare professionals than the ones engaged by the Italian National Health System. Nevertheless, $31.6 \%$ stated that healthcare providers have an economic interest in child immunization, and 35.5\% declared that healthcare professionals inform only on vaccinations benefits not on risks. Moreover, the Italian vaccination schedule was considered too inflexible to adapt to changing parents' needs in $42.8 \%$ of questionnaires, and $38 \%$ of the women claimed that people who do not vaccinate are blamed by healthcare service. Concerning vaccines, $21.7 \%$ of the sample thought that they are an imposition, and $44.6 \%$ thought that they are more useful for society than for the individual. Furthermore, the majority of interviewed women (81.6\%) were in favour of compulsory vaccination. Most women of the sample (81.6\%) declared to be in favour of mandatory vaccinations, $13.8 \%$ were against them and $4.5 \%$ did not answer to the question.

\subsection{Univariate analysis}

In Table 1, the main demographic, occupational and social features of the sample are described, stratified by the propensity towards compulsory vaccinations. Women from the North of Italy had a higher propensity for mandatory vaccination ( $90.1 \%$ of them) than did the women from the Centre and the South $(83.1 \%$ and $82.1 \%$ respectively; $\mathrm{p}<0.001)$. Women older than 33 agreed more on mandatory vaccination than did the younger women (87.2 vs 83.7\%; $\mathrm{p}=0.04$ ), and women who were married or lived with a partner agreed more than did single or divorced women $(86.3 \%$ vs $76.3 \%$; $\mathrm{p}=0.04)$. Moreover, women who wanted to vaccinate their next child were more inclined towards compulsory vaccination (87\%) than did the rest of the sample (19.4\%; p < 0.001$)$.

Table 2 shows the main differences regarding the information sources between women who agreed and disagreed with mandatory vaccination. Women who used institutional information leaflets had a higher propensity for compulsory vaccination than that of women who did not use this kind of information source $(88.5 \%$ 
vs $84.2 \%$; $\mathrm{p}=0.03$ ) or women who went to vaccination clinics to obtain information (88.6\% vs $84.6 \%$; $\mathrm{p}=0.05$ ). Conversely, women who went to a private healthcare professional were less inclined towards compulsory vaccination than were the other women (80.9\% vs $86 \%$; $p=0.05$ ) or people who got information from anti-vaccination movements (69.7\% vs $86.8 \%$; $<<0.001$ ).

Table 3 describes the association between the trust in health care system and the propensity towards compulsory vaccination. The analysis shows that women who had confidence in healthcare professional information agreed more on mandatory vaccination than did the following: the rest of the sample (87.7\% vs $55 \%$; p < $0.001)$; women who declared that healthcare professionals are experienced and knowledgeable (87.2\% vs $70.2 \%$; $<0.001)$; and those who considered the Italian vaccination schedule flexible (87\% vs $82.5 \%$; $\mathrm{p}=0.02$ ).

Women who trusted more private healthcare professionals than the ones engaged by the Italian NHS agreed less to mandatory vaccination $(79.6 \%$ vs $87.1 \%$; $<0.001$ ). The propensity towards compulsory vaccination was lower among women who stated that healthcare providers have an economic interest in child immunization (77\% vs $89.8 \%$; $\mathrm{p}<0.001$ ) and among the women who declared that healthcare providers inform only on vaccination benefits and not on risks (78.3\% vs $90.1 \%$; p < 0.001 ). Furthermore, the women that claimed that people who do not vaccinate are blamed by healthcare service were less inclined towards mandatory vaccination than the rest of the sample ( $82.9 \%$ vs $87.1 \%, \mathrm{p}<0.001)$ or women who thought that vaccines are an imposition (79\% vs 87.6\%; $\mathrm{p}<0.001$ ).

\subsection{Multivariate analysis}

These results were partially confirmed in the logistic regression model (Table 4): women who want to vaccinate their next child were more inclined towards compulsory vaccination than was the rest of the sample (OR: $11.83,95 \% \mathrm{CI}: 3.74-37.45, \mathrm{p}<0.001$ ). Moreover, women who went to vaccination clinics to obtain information had a higher propensity for mandatory vaccination (OR: $1.90,95 \% \mathrm{CI}: 1.22-2.95, \mathrm{p}=0.01$ ), as opposed to women who obtained information from anti-vaccination movements compared to the others (OR: $0.35,95 \% \mathrm{CI}: 0.21-0.58, \mathrm{p}<0.001$ ). Furthermore, women who had confidence in healthcare professional information agreed more on mandatory vaccination than did the other women (OR: 2.66, 95\% CI: 1.62-4.36, p < 0.001). In contrast, people who stated that healthcare professionals have an economic interest in child immunization and who declared that healthcare providers inform only on vaccinations benefits not on risks were less likely to agree on compulsory vaccination (OR: $0.66,95 \% \mathrm{CI}$ : $0.46-0.96$, $\mathrm{p}=0.03$; OR: 0.66, 95\% CI: 0.46-0.95, p =0.03, respectively).

\section{Discussion}

The implementation of a compulsory vaccination programme represents a turning point in vaccination plans in Italy [19]. Ethical, political and scientific debate on mandatory vaccinations is an interesting topic. The major aim of this study is to assess pregnant women's attitudes towards the compulsory nature of paediatric vaccination and to identify the main factors influencing these attitudes.

The results show an interesting association between information sources and attitudes towards compulsory vaccination. In fact, mandatory vaccination is more easily accepted among women who seek information in vaccination clinics. With no surprise, the few women obtaining information from anti-vaccine associations are less prone to accept mandatory vaccination plans. A paper published in Vaccine in 2015 by SAGE Working Group on Vaccine Hesitancy proposed the "3Cs" model [12]. In this model, a key role in determining the acceptance of vaccination was played by the confidence in the health system and in the reliability and competence of the health services and health professionals. Comparable results are shown in the NAVIDAD study. In fact, women who stated that healthcare professionals have an economic interest in childhood immunization and who declared that healthcare providers inform only on vaccinations benefits were less likely to agree on compulsory vaccination. To be clear, vaccine hesitancy, defined as a delay or refusal in accepting vaccination [12], is slightly different from attitudes towards compulsory vaccination. Nevertheless, the results from the NAVIDAD study show that there is a strong association between the acceptance of mandatory vaccination and the intention to vaccinate the next child. This association can explain by the observed differences in opinion between regions. The atti-

Table 1

Factors influencing propensity towards vaccination.

\begin{tabular}{|c|c|c|c|c|c|c|}
\hline & & \multicolumn{5}{|c|}{ In favour of mandatory vaccination } \\
\hline & & \multicolumn{2}{|c|}{ Yes $(n=1486)$} & \multicolumn{2}{|c|}{ No $(n=252)$} & \multirow[t]{2}{*}{$\mathrm{P}^{*}$} \\
\hline & & $\%$ & $\mathrm{~N}$ & $\%$ & $\mathrm{~N}$ & \\
\hline \multirow[t]{3}{*}{ Region } & North $(n=686)$ & 90.1 & 618 & 9.9 & 68 & $<0.001$ \\
\hline & Centre $(n=432)$ & 83.1 & 359 & 16.9 & 73 & \\
\hline & South $(n=620)$ & 82.1 & 509 & 17.9 & 111 & \\
\hline \multirow[t]{2}{*}{ Nationality } & Italian $(\mathrm{n}=1583)$ & 85.3 & 1350 & 14.7 & 233 & 0.43 \\
\hline & Foreign $(n=139)$ & 87.8 & 122 & 12.2 & 17 & \\
\hline \multirow[t]{2}{*}{ Age (years) } & $<33(\mathrm{n}=859)$ & 83.7 & 719 & 16.3 & 140 & 0.04 \\
\hline & $\geq 33(\mathrm{n}=874)$ & 87.2 & 762 & 12.8 & 112 & \\
\hline \multirow[t]{2}{*}{ Marital status } & Cohabiting/married $(\mathrm{n}=1596)$ & 86.3 & 1377 & 13.7 & 219 & 0.01 \\
\hline & Single/divorced $(n=135)$ & 76.3 & 103 & 23.7 & 32 & \\
\hline \multirow[t]{2}{*}{ Educational level } & High School or inferior $(n=921)$ & 85.0 & 783 & 15.0 & 138 & 0.56 \\
\hline & College degree $(n=815)$ & 86.0 & 701 & 14.0 & 114 & \\
\hline \multirow[t]{5}{*}{ Employment } & Office workers or teachers $(n=696)$ & 86.8 & 604 & 13.2 & 92 & 0.17 \\
\hline & Entrepreneurs or freelance professionals $(n=250)$ & 83.6 & 209 & 16.4 & 41 & \\
\hline & Labourers or artisans $(n=159)$ & 89.3 & 142 & 10.7 & 17 & \\
\hline & Healthcare professional $(n=138)$ & 87.0 & 120 & 13.0 & 18 & \\
\hline & Unemployed $(n=485)$ & 82.9 & 402 & 17.1 & 83 & \\
\hline \multirow[t]{2}{*}{ Previous deliveries } & One or more $(n=1096)$ & 85.7 & 939 & 14.3 & 157 & 0.85 \\
\hline & None $(n=641)$ & 85.3 & 547 & 14.7 & 94 & \\
\hline \multirow[t]{2}{*}{ Vaccination intention } & No $(\mathrm{n}=31)$ & 19.4 & 6 & 80.6 & 25 & $<0.001$ \\
\hline & Yes $(n=1678)$ & 87.0 & 1460 & 13.0 & 218 & \\
\hline
\end{tabular}

Chi-squared test, significance level $\mathrm{P} \leq 0.05$. 
Table 2

Vaccines information sources according to propensity towards vaccination.

\begin{tabular}{|c|c|c|c|c|c|c|}
\hline & & \multicolumn{5}{|c|}{ In favour of mandatory vaccination } \\
\hline & & \multicolumn{2}{|c|}{ Yes $(n=1486)$} & \multicolumn{2}{|c|}{ No $(n=252)$} & \multirow[t]{2}{*}{$\mathrm{P}^{*}$} \\
\hline & & $\%$ & $\mathrm{~N}$ & $\%$ & $\mathrm{~N}$ & \\
\hline \multirow[t]{2}{*}{ Healthcare professional } & No $(n=995)$ & 85.4 & 850 & 14.6 & 145 & \multirow[t]{2}{*}{0.88} \\
\hline & Yes $(n=720)$ & 85.7 & 617 & 14.3 & 103 & \\
\hline \multirow[t]{2}{*}{ Autonomous information } & No $(n=726)$ & 86.2 & 626 & 13.8 & 100 & \multirow[t]{2}{*}{0.45} \\
\hline & Yes $(n=989)$ & 84.9 & 840 & 15.1 & 149 & \\
\hline \multirow[t]{2}{*}{ General pratictioner } & No $(\mathrm{n}=1238)$ & 84.8 & 1050 & 15.2 & 188 & \multirow[t]{2}{*}{0.26} \\
\hline & Yes $(n=475)$ & 86.9 & 413 & 13.1 & 62 & \\
\hline \multirow[t]{2}{*}{ Gynecologist } & No $(n=1439)$ & 85.1 & 1224 & 14.9 & 215 & \multirow[t]{2}{*}{0.35} \\
\hline & Yes $(n=274)$ & 87.2 & 239 & 12.8 & 35 & \\
\hline \multirow[t]{2}{*}{ Pediatrician } & No $(n=1060)$ & 84.9 & 900 & 15.1 & 160 & \multirow[t]{2}{*}{0.43} \\
\hline & Yes $(n=650)$ & 86.3 & 561 & 13.7 & 89 & \\
\hline \multirow[t]{2}{*}{ Institutional information leaflets } & No $(n=1236)$ & 84.2 & 1041 & 15.8 & 195 & \multirow[t]{2}{*}{0.03} \\
\hline & Yes $(n=477)$ & 88.5 & 422 & 11.5 & 55 & \\
\hline \multirow[t]{2}{*}{ Vaccination clinics } & No $(n=1353)$ & 84.6 & 1144 & 15.4 & 209 & \multirow[t]{2}{*}{0.05} \\
\hline & Yes $(n=360)$ & 88.6 & 319 & 11.4 & 41 & \\
\hline \multirow[t]{2}{*}{ Institutional web sites } & No $(n=1147)$ & 84.7 & 971 & 15.3 & 176 & \multirow[t]{2}{*}{0.21} \\
\hline & Yes $(n=566)$ & 86.9 & 492 & 13.1 & 74 & \\
\hline \multirow[t]{2}{*}{ Non-institutional web sites } & No $(n=1133)$ & 85.5 & 969 & 14.5 & 164 & \multirow[t]{2}{*}{0.83} \\
\hline & Yes $(n=579)$ & 85.1 & 493 & 14.9 & 86 & \\
\hline \multirow[t]{2}{*}{ Smartphone and tablet applications } & No $(n=1645)$ & 85.5 & 1406 & 14.5 & 239 & \multirow[t]{2}{*}{0.63} \\
\hline & Yes $(n=66)$ & 83.3 & 55 & 16.7 & 11 & \\
\hline \multirow[t]{2}{*}{ Freelance healthcare professional } & No $(n=1504)$ & 86.0 & 1294 & 14.0 & 210 & \multirow[t]{2}{*}{0.05} \\
\hline & Yes $(n=209)$ & 80.9 & 169 & 19.1 & 40 & \\
\hline \multirow[t]{2}{*}{ Prenatal course } & No $(n=1378)$ & 84.7 & 1167 & 15.3 & 211 & \multirow[t]{2}{*}{0.09} \\
\hline & Yes $(n=335)$ & 88.4 & 296 & 11.6 & 39 & \\
\hline \multirow[t]{2}{*}{ Word of mouth } & No $(\mathrm{n}=874)$ & 85.8 & 750 & 14.2 & 124 & 0.62 \\
\hline & Yes $(n=838)$ & 85.0 & 712 & 15.0 & 126 & \\
\hline Mass media & No $(\mathrm{n}=1089)$ & 85.1 & 927 & 14.9 & 162 & 0.66 \\
\hline & Yes $(n=624)$ & 85.9 & 536 & 14.1 & 88 & \\
\hline Antivaccination movements & No $(n=1577)$ & 86.8 & 1369 & 13.2 & 208 & $<0.001$ \\
\hline & Yes $(n=132)$ & 69.7 & 92 & 30.3 & 40 & \\
\hline
\end{tabular}

Chi-squared test, significance level $\mathrm{P}<0.05$.

Table 3

Trust in health care system according to propensity towards vaccination.

\begin{tabular}{|c|c|c|c|c|c|c|}
\hline & & \multicolumn{5}{|c|}{ In favour of mandatory vaccination } \\
\hline & & \multicolumn{2}{|c|}{ Yes $(n=1486)$} & \multicolumn{2}{|c|}{ No $(n=252)$} & \multirow[t]{2}{*}{$\mathrm{p}$} \\
\hline & & $\%$ & $\mathrm{~N}$ & $\%$ & $\mathrm{~N}$ & \\
\hline \multirow{2}{*}{ Confidence in healthcare professional information } & Disagree/Strongly disagree $(n=120)$ & 55.0 & 66 & 45.0 & 54 & \multirow[t]{2}{*}{$<0.001$} \\
\hline & Agree/Strongly agree $(n=1605)$ & 87.7 & 1408 & 12.3 & 197 & \\
\hline \multirow[t]{2}{*}{ Experienced and knowledgeable healthcare professional } & Disagree/Strongly disagree $(\mathrm{n}=171)$ & 70.2 & 120 & 29.8 & 51 & \multirow[t]{2}{*}{$<0.001$} \\
\hline & Agree/Strongly agree $(n=1513)$ & 87.2 & 1320 & 12.8 & 193 & \\
\hline \multirow[t]{2}{*}{ More confidence in freelance healthcare professional } & Disagree/Strongly disagree $(\mathrm{n}=1367)$ & 87.1 & 1191 & 12.9 & 176 & \multirow[t]{2}{*}{$<0.001$} \\
\hline & Agree/Strongly agree $(n=323)$ & 79.6 & 257 & 20.4 & 66 & \\
\hline \multirow[t]{2}{*}{ Vaccine refusers blamed by healthcare professional } & Disagree/Strongly disagree $(n=971)$ & 87.1 & 846 & 12.9 & 125 & \multirow[t]{2}{*}{0.02} \\
\hline & Agree/Strongly agree $(n=671)$ & 82.9 & 556 & 17.1 & 115 & \\
\hline \multirow[t]{2}{*}{ Flexibility of Italian vaccination schedule } & Disagree/Strongly disagree $(n=743)$ & 82.5 & 613 & 17.5 & 130 & \multirow[t]{2}{*}{0.02} \\
\hline & Agree/Strongly agree $(n=731)$ & 87.0 & 636 & 13.0 & 95 & \\
\hline \multirow[t]{2}{*}{ Vaccines more useful for the society than for the individual } & Disagree/Strongly disagree $(n=916)$ & 86.2 & 790 & 13.8 & 126 & \multirow[t]{2}{*}{0.31} \\
\hline & Agree/Strongly agree $(n=774)$ & 84.5 & 654 & 15.5 & 120 & \\
\hline \multirow[t]{2}{*}{ Healthcare professional's economic interest } & Disagree/Strongly disagree $(n=1123)$ & 89.8 & 1009 & 10.2 & 114 & \multirow[t]{2}{*}{$<0.001$} \\
\hline & Agree/Strongly agree $(n=540)$ & 77.0 & 416 & 23.0 & 124 & \\
\hline \multirow[t]{2}{*}{ Information only on vaccinations benefits not on risks } & Disagree/Strongly disagree $(n=1050)$ & 90.1 & 946 & 9.9 & 104 & \multirow[t]{2}{*}{$<0.001$} \\
\hline & Agree/Strongly agree $(n=614)$ & 78.3 & 481 & 21.7 & 133 & \\
\hline \multirow[t]{2}{*}{ Vaccines imposition } & Disagree/Strongly disagree $(n=1325)$ & 87.6 & 1161 & 12.4 & 164 & \multirow[t]{2}{*}{$<0.001$} \\
\hline & Agree/Strongly agree $(n=376)$ & 79.0 & 297 & 21.0 & 79 & \\
\hline
\end{tabular}

"Chi-squared test, significance level $\mathrm{P}<0.05$.

tudes towards compulsory vaccination are in line with the immunization level recorded in 2016 along the entire peninsula [16,17].

Furthermore, different studies show how decisions about vaccination are made during pregnancy $[33,34]$ and, in particular, first time mothers are more vaccine hesitant and undecided about childhood vaccination [35]. For these reason, multicomponent and dialogue-based interventions should be considered because strategies should be carefully tailored according to the target population, their reasons for hesitancy, and the specific context [36].
A cross-sectional study has some limitations due to the study design. No causality can be proven. Therefore, this survey is an assessment tool with some limitations [37]. First, there is the personal predisposition to complete the questionnaire; people refusing to answer the question might be shy or introspective. This aspect represents a possible loss of part of the sample. Our effort, though, was meant to resize this problem by using trained resident doctors in the administration of the questionnaires to enable us to gain greater compliance and completeness of the questionnaire. 
Table 4

Association between socio-demografic data, vaccines information sources and trust in health care system and the propensity towards mandatory vaccination.

\begin{tabular}{|c|c|c|c|c|}
\hline & & \multicolumn{3}{|c|}{ Propensity towards mandatory vaccination } \\
\hline & & Adj OR & $95 \% \mathrm{CI}$ & $\mathrm{P}^{* *}$ \\
\hline \multirow[t]{3}{*}{ Region } & North & 1 & & \\
\hline & Centre & 2.00 & 1.32-3.01 & 0.01 \\
\hline & South & 1.10 & $0.74-1.64$ & \\
\hline \multirow[t]{2}{*}{ Vaccination intention } & No & 1 & & $<0.001$ \\
\hline & Yes & 11.83 & 3.74-37.45 & \\
\hline \multirow[t]{2}{*}{ Vaccination clinics } & No & 1 & & 0.01 \\
\hline & Yes & 1.90 & 1.22-2.95 & \\
\hline \multirow[t]{2}{*}{ Antivaccination movements } & No & 1 & & $<0.001$ \\
\hline & Yes & 0.35 & $0.21-0.58$ & \\
\hline \multirow[t]{2}{*}{ Confidence in healthcare professional information } & Disagree/Strongly disagree & 1 & & $<0.001$ \\
\hline & Agree/Strongly agree & 2.66 & $1.62-4.36$ & \\
\hline \multirow[t]{2}{*}{ Healthcare professional's economic interest } & Disagree/Strongly disagree & 1 & & 0.03 \\
\hline & Agree/Strongly agree & 0.66 & $0.46-0.96$ & \\
\hline \multirow[t]{2}{*}{ Information only on vaccinations benefits not on risks } & Disagree/Strongly disagree & 1 & & 0.03 \\
\hline & Agree/Strongly agree & 0.66 & $0.46-0.95$ & \\
\hline
\end{tabular}

Statistically significant results are reported in bold.

* Adjusted for region, age, marital status, employment, vaccination intention, source of information (institutional information leaflets, vaccination clinics, institutional web

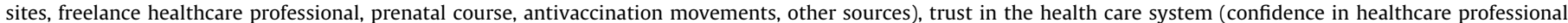

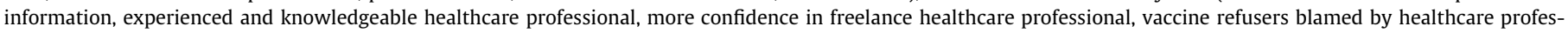
sional, flexibility of Italian vaccination schedule, healthcare professional's economic interest, information only on vaccinations benefits not on risks, vaccines imposition).

Significance level $\mathrm{P}<0.05$.

Another limitation is due to a potential loss of pregnant women that are under the care of private gynaecologists and do not attend the public hospitals. These reasons can explain why some characteristics could appear unexpected. In particular, the educational level and employment were different from what would be predicted based on national data [38]. Interestingly, our data are consistent with the results of similar studies published in other international peer reviewed journals in the current literature. In fact, a broad spectrum of results can be found [39,40]. In addition, as shown in the results of our research, neither educational level nor employment appear to affect the attitudes towards mandatory vaccination.

Resident doctors who performed the interviews were recognizable as physician, which could be considered a limitation. The women in this study might have been more hesitant to communicate their true opinions and beliefs about vaccines to healthcare providers. It has to be considered that the interviewers were not directly employed by the hospital or as part of the study participants' care teams, and using trained resident doctors in questionnaires administration enabled us to gain greater compliance and completeness of the questionnaire.

The main strength of our study is represented by the multicentre design that allows not only to generalize the results and consider the phenomenon in the overall country but also to analyse differences related to geographical origin. This study was conducted in fourteen Italian cities that are very different in terms of population and geographical location. Turin, Rome and Naples for example, are three densely populated towns, the first one located in the north, the second in the centre and the third in the south of Italy, while Ferrara, Siena and Chieti are smaller cities with a population not exceeding the 150,000 inhabitants, equally distributed along the whole Italian peninsula.

Furthermore, to the best of our knowledge, there is no other study that evaluates the factors that can have an influence on the acceptance of a compulsory vaccine plan. Furthermore, the results can be easily generalized to the Italian population due to the wide sample size and the number of centres involved. It has to be stated that this study has been performed before Italy's law 119/2017 that makes ten vaccines mandatory for infants. As reported in The Lancet Infectious Disease by Signorelli et al. [20], mandatory vaccination appears to be an effective tool to increase vaccine coverage, and the results are encouraging. For this reason, it is desir- able that policy makers take account of the results from the NAVIDAD study. In particular, the global effect on the reliability of health system and professionals should be considered.

\section{Ethical standards}

The authors assert that all procedures contributing to this work comply with the ethical standards of the relevant national and institutional committees on human experimentation and with the 1964 Declaration of Helsinki and its later amendments.

\section{Acknowledgements}

The authors declare that no funding or grants were received to carry out the present research.

\section{Conflict of interest}

The authors declare that they have no conflicts of interest.

\section{Appendix A. Supplementary material}

Supplementary data associated with this article can be found, in the online version, at https://doi.org/10.1016/j.vaccine.2018.04. 029.

\section{References}

[1] Plotkin S. History of vaccination. Proc Natl Acad Sci U S A 2014;111 (34):12283-7.

[2] Ozawa S, Mirelman A, Stack ML, Walker DG, Levine OS. Cost-effectiveness and economic benefits of vaccines in low- and middle-income countries: a systematic review. Vaccine. 2012;31(1):96-108.

[3] Newall AT, Jit M, Hutubessy R. Are current cost-effectiveness thresholds for low- and middle-income countries useful? Examples from the world of vaccines. PharmacoEconomics. 2014;32(6):525-31.

[4] World Health Organization. 10 facts about immunization. [Internet]. [Accessed march 2018]. Available at: http://www.who.int/features/factfiles/ immunization/en/

[5] World Health Organization. SAGE Assessment Report of the Global Vaccine Action Plan [Accessed: March 2018] Available at: http://www.who.int/ immunization/web_2017_sage_gvap_assessment_report_en.pdf?ua=1, ; 2017.

[6] World Health Organization. Global Vaccine Action Plan 2011-2020. [Accessed March 2018]. Available at: http://www.who.int/immunization/global_ vaccine_action_plan/GVAP_doc_2011_2020/en/ 
[7] World Health Organization, Regional Office for Europe. European Vaccine Action Plan (2015 - 2020) [Accessed March 2018]. Available at: http://www. euro.who.int/_data/assets/pdf_file/0007/255679/WHO_EVAP_UK_v30_WEBx. pdf

[8] Nowak GJ, Gellin BG, MacDonald NE, Butler R. SAGE working group on vaccine hesitancy. addressing vaccine hesitancy: the potential value of commercial and social marketing principles and practices. Vaccine 2015;33(34):4204-11.

[9] Larson HJ, Jarrett C, Eckersberger E, Smith DMD, Paterson P. Understanding vaccine hesitancy around vaccines and vaccination from a global perspective: a systematic review of published literature, 2007-2012. Vaccine 2014;32 (19):2150-9.

[10] Dubé E, Vivion M, MacDonald NE. Vaccine hesitancy, vaccine refusal and the anti-vaccine movement: influence, impact and implications. Expert Rev Vaccines 2015;14(1):99-117.

[11] Dubé E, Gagnon D, Nickels E, Jeram S, Schuster M. Mapping vaccine hesitancyCountry-specific characteristics of a global phenomenon. Vaccine 2014;32 (49):6649-54.

[12] MacDonald NE. SAGE working, group on vaccine hesitancy. vaccine hesitancy: definition, scope and determinants. Vaccine 2015;33(34):4161-4.

[13] Hickler B, Guirguis S, Obregon R. Vaccine special issue on vaccine hesitancy. Vaccine 2015;33(34):4155-6.

[14] Odone A, Signorelli C. When vaccine hesitancy makes headlines. Vaccine 2017;35(9):1209-10.

[15] Consiglio Superiore di Sanità. Piano Nazionale Prevenzione Vaccinale (PNPV) 2016-2018 [Accessed March 2018]. Available at: http://www.adnkronos.com/ r/Pub/AdnKronos/Assets/PDF/piano_prevenzione_vaccini.pdf

[16] Ministero della Salute. Coperture vaccinali a 24 mesi (per 100 abitanti). Anno 2016 (Coorte 2014) [Accessed March 2018]. Available at: http://www. salute.gov.it/imgs/C_17_tavole_20_allegati_iitemAllegati_0_fileAllegati_ itemFile_5_file.pdf

[17] Istituto Superiore di Sanità. Copertura vaccinale in Italia. [Accessed March 2018]. Available at: http://www.epicentro.iss.it/temi/vaccinazioni/dati_Ita.asp

[18] Ministero della Salute. Vaccinazioni, i dati 2016: in calo le coperture dall'infanzia all'adolescenza. [Accessed March 2018]. Available at: http:// www.salastampa.salute.gov.it/portale/news/p3_2_1_1_1.jsp?lingua=italiano\& menu=notizie\&p=dalministero\&id $=2971$

[19] Legge n.119/17. Disposizioni urgenti in materia di prevenzione vaccinale. Available at: http://www.gazzettaufficiale.it/eli/id/2017/08/5/17G00132/sg

[20] Signorelli C, Iannazzo S, Odone A. The imperative of vaccination put into practice. Lancet Infect Dis 2018;18(1):26-7.

[21] Forbes TA, McMinn A, Crawford N, Leask J, Danchin M. Vaccination uptake by vaccine-hesitant parents attending a specialist immunization clinic in Australia. Hum Vaccines Immunother 2015;11(12):2895-903.

[22] Brown KF, Kroll JS, Hudson MJ, Ramsay M, Green J, Long SJ, et al. Factors underlying parental decisions about combination childhood vaccinations including MMR: a systematic review. Vaccine 2010;28(26):4235-48.

[23] Weiner JL, Fisher AM, Nowak GJ, Basket MM, Gellin BG. Childhood Immunizations: first-time expectant mothers' Knowledge, Beliefs, Intentions, and Behaviors. Am J Prev Med 2015;49(6 Suppl 4):S426-34.

[24] Mollema L, Wijers N, Hahné SJM, van der Klis FRM, Boshuizen HC, de Melker HE. Participation in and attitude towards the national immunization program in the Netherlands: data from population-based questionnaires. BMC Public Health 2012:12:57.

[25] Signorelli C, Odone A, Cella P, Iannazzo S, D’Ancona F, Guerra R. Infant immunization coverage in Italy (2000-2016). Ann Ist Super Sanita 2017;53 (3):231-7.

[26] Scaioli G, Bert F, Galis V, Brusaferro S, De Vito E, La Torre G, et al. Pregnancy and internet: sociodemographic and geographic differences in e-health practice. Results from an Italian multicenter study. Public Health 2015;129 (9):1258-66.

[27] Bert F, Passi S, Scaioli G, Gualano MR, Siliquini R. There comes a baby! What should I do? Smartphones' pregnancy-related applications: a web-based overview. Health Informatics J. 2016:22(3):608-17.

[28] ISTAT. Popolazione per classi di Età Scolastica 2016 - Italia [Accessed March 2018]. Available at: https://www.tuttitalia.it/statistiche/popolazione-etascolastica-2016

[29] Pourhoseingholi MA, Vahedi M, Rahimzadeh M. Sample size calculation in medical studies. Gastroenterol Hepatol Bed Bench 2013;6(1):14-7.

[30] Habib A, Johargy A, Mahmood K. Design and determination of the sample size in medical research - PDF. IOSR J Dental Med Sci 2014:13(5):21-31.

[31] Charan J, Biswas T. How to calculate sample size for different study designs in medical research? Indian J Psychol Med 2013;35(2):121-6.

[32] Hosmer DW, Lemeshow S. Multiple Logistic Regression. In: Applied Logistic Regression. John Wiley \& Sons, Inc.; 2000. Available at: http://onlinelibrary. wiley.com/doi/10.1002/0471722146.ch2/summary

[33] Glanz JM, Wagner NM, Narwaney KJ, Shoup JA, McClure DL, McCormick EV, et al. A mixed methods study of parental vaccine decision making and parentprovider trust. Acad Pediatr 2013;13(5):481-8.

[34] Benin AL, Wisler-Scher DJ, Colson E, Shapiro ED, Holmboe ES. Qualitative analysis of mothers' decision-making about vaccines for infants: The importance of trust. Pediatrics 2006;117(5):1532-41.

[35] Danchin MH, Costa-Pinto J, Attwell K, Willaby H, Wiley K, Hoq M, et al. Vaccine decision-making begins in pregnancy: correlation between vaccine concerns, intentions and maternal vaccination with subsequent childhood vaccine uptake. Vaccine 2017. https://doi.org/10.1016/i.vaccine.2017.08.003.

[36] Jarrett C, Wilson R, O'Leary M, Eckersberger E, Larson HJ. SAGE working group on vaccine hesitancy. strategies for addressing vaccine hesitancy - a systematic review. Vaccine 2015;33(34):4180-90.

[37] Gualano MR, Bontempi C, Saulle R, Ricciardi W, La Torre G. Validation of the global health professions students survey questionnaire in Italy. Ital J Public Health 2011:8(4):392-8.

[38] ISTAT. ItaliaInCifre2015It.pdf [Accessed March 2018]. Available at: https:// www.istat.it/it/files/2015/08/ItaliaInCifre2015It.pdf

[39] Esposito G, Ambrosio R, Napolitano F, Di Giuseppe G. Women's Knowledge, Attitudes and Behavior about Maternal Risk Factors in Pregnancy. PLoS ONE. 2015;10(12). Available at: https://www.ncbi.nlm.nih.gov/pmc/articles/ PMC4694714/

[40] Agricola E, Gesualdo F, Alimenti L, Pandolfi E, Carloni E, D'Ambrosio A, et al. Knowledge attitude and practice toward pertussis vaccination during pregnancy among pregnant and postpartum Italian women. Hum Vaccines Immunother 2016;12(8):1982-8. 